\title{
Yes We Can? A Política Externa de Obama para a América Latina: Da Decepção à Autonomização da Região*
}

\section{Sandra Colombo** e J. Ignacio Frechero***}

"Yes we can to justice and equality. Yes we can to opportunity and prosperity.

Yes we can heal this nation. Yes we can repair this world. Yes we can."

- Barack Obama

"Todos pensam em mudar o mundo, mas ninguém pensa em mudar a si mesmo."

- Leon Tolstoi

\section{A administração do presidente Barack H. Obama nos Estados Uni- dos, que suscitou grandes expectativas e esperanças em seu começo,}

\footnotetext{
* Artigo recebido em 11 de julho de 2012 e aprovado para publicação em 30 de novembro de 2012. Traduzido por Victor Coutinho Lage. E-mail: victorcoutinholage@yahoo.com.br. Os autores agradecem as sugestões e contribuições dos revisores.

** Doutora em Sociologia pela Universidade Estadual Paulista (UNESP), professora de licenciatura em Relações Internacionais da Universidad Nacional del Centro de la Provincia de Buenos Aires (UNCPBA) e pesquisadora do Centro de Estudios Interdisciplinarios en Problemáticas Internacionales y Locales (CEIPIL). E-mail: s_s_colombo@yahoo.com.

*** Doutorando em Ciência Política pela Universidad Nacional de San Martín (UNSAM), bolsista Tipo II do Consejo Nacional de Investigaciones Científicas y Técnicas (CONICET), e pesquisador do CEIPIL. E-mail: ifrechero@yahoo.com.ar.
}

CONTEXTO INTERNACIONAL Rio de Janeiro, vol. 34, noำ 1, janeiro/junho 2012, p. 189-222. 
cumpriu seu primeiro mandato e se encaminha para o segundo, depois de derrotar o candidato republicano, Mitt Romney, na disputa eleitoral de 2012. Tem-se, portanto, um momento oportuno para se observar e contribuir para o debate sobre o desempenho do governo democrata, no que diz respeito à sua política externa entre janeiro de 2009 e o final de 2012.

Este artigo busca investigar, descrever e refletir sobre o estado atual da política externa dos Estados Unidos para a América Latina, através de uma análise descritiva dos itens da agenda e do conteúdo da política externa, considerando a sua implementação em dois níveis de projeção: o regional, que abordaremos na primeira parte, e o bilateral, abordado na segunda parte, com base nos casos da Venezuela, do Brasil e da Argentina.

Como objetivos específicos, pretendemos abarcar duas preocupações. Primeiro, as razões e a natureza da decepção regional em relação à política hemisférica da administração Obama. Argumentamos que o governo democrata não cumpriu as plausíveis promessas de mudança feitas na campanha eleitoral; para isso, mostramos continuidades de algumas das ações, decisões e características de sua política externa para a América Latina, em relação ao período de George W. Bush.

A segunda preocupação refere-se a como se manifesta e como se reforça o distanciamento político-estratégico entre os Estados Unidos e os três países selecionados, à luz de fatores como a inércia na política externa, a ausência de uma nova e ativa estratégia diplomática e a autonomia crescente da região.

\section{Obama e a Política Externa para a América Latina}

Como critério central em sua ação internacional, a administração Obama buscou diferenciar-se de seu antecessor republicano, um pre- 
sidente que colocara a região fora do radar de Washington (GEDDA, 2004) e que terminara seu mandato desprestigiado e com altos índices de rejeição no exterior. ${ }^{1}$ Dessa forma, essa atitude anti-Bush (LIEBERMAN, 2009) relegou alguns elementos, tais como o messianismo democrático, o unilateralismo e a ênfase em recursos materiais de poder, concedendo prioridade a uma postura mais conciliatória, cooperativa e humanitária, alinhada à noção de smart power, $^{2}$ expressa em sua disposição de fechar a prisão de Guantánamo, no anúncio de término da Guerra do Iraque ou em sua aproximação com o Mundo Islâmico. ${ }^{3}$

Entretanto, essa intenção transformadora coexistiu com a manutenção de elementos-chave da projeção global de poder dos Estados Unidos, como a continuidade da luta com a Al Qaeda, juntamente com sua expansão a novos cenários e sob novas formas - no marco da menor presença no Iraque e no Afeganistão -; a vigência do recurso à intervenção militar, agora com características humanitárias - Haiti e Líbia -; o aumento constante de bases no exterior; o maior orçamento de Defesa; ${ }^{4}$ e o reforço de alianças de segurança na grande região da Ásia-Pacífico.

No caso da América Latina, a vitória de Barack Obama nas eleições despertou grandes esperanças acerca da possibilidade de construir uma relação interamericana mais estreita em termos de cooperação, distante dos arquétipos da Guerra Fria e da presunção hegemônica. ${ }^{5}$ Motivaram esses anseios a singularidade histórica de se ter o primeiro afrodescendente a chegar à Casa Branca - exaltada pelo marketing político doméstico ${ }^{6}{ }^{6}$ e a aspiração de que, como expoente de uma minoria que tem sofrido a escravidão e a marginalização, Obama seria condescendente com as demandas de longo prazo dos países e povos americanos.

Não há dúvida de que o presidente democrata alimentou tais esperanças com um discurso de forte apelo à mudança. Nesse sentido, embo- 
ra os temas hemisféricos tenham ficado bastante relegados no conjunto dos conteúdos de sua campanha para a Casa Branca (ERIKSON, 2008, p. 103), sua principal carta de apresentação para a região foi o discurso "Renewing U.S. Leadership in the Americas" (Renovando a Liderança dos EUA nas Américas), proferido em 28 de maio de 2008 na Fundação Cubano Americana. Na oportunidade, Obama buscou capitalizar o importante voto latino ao criticar o desempenho hemisférico de Bush, por ter sido "negligente com nossos amigos, ineficaz com nossos adversários, desinteressado nos desafios que importam para as pessoas e incapaz de promover nossos interesses na região" (OBAMA, 2008).

Como contrapartida, Obama propôs uma nova aliança hemisférica, distante da arrogância com que historicamente a superpotência ditou condições à região. Além disso, fez propostas assaz concretas, com destaque para a eventual designação de enviado especial para o hemisfério, um acordo energético multilateral, a revisão dos tratados de livre-comércio em negociação, o aumento da ajuda, uma renovada política para Cuba e, por último, porém não menos relevante, a realização da postergada reforma imigratória. Com isso, todos os governos da região felicitaram a vitória de Obama em 4 de novembro de 2008 e celebraram o fim do predomínio republicano. ${ }^{7}$

Assim que se instalou no Salão Oval, o democrata buscou rapidamente instituir vínculos com seus pares regionais, recebendo as visitas oficiais de Lula, do Brasil, Michelle Bachelet, do Chile, e Álvaro Uribe, da Colômbia; a isso, somaram-se seu encontro, como presidente eleito, com Felipe Calderón, do México, a breve reunião entre a secretária de Estado, Hillary Clinton, e o presidente haitiano, René Preval, e as viagens do vice-presidente, Joe Biden, a Costa Rica e Chile, em março de 2009.

Seguindo o mesmo caminho, os países da região receberam com aprovação a primeira medida drástica de Obama na demonstração de 
sua atitude anti-Bush em nível mundial: a disposição - logo fracassada - de fechar a prisão de Guantánamo, em Cuba. Esse gesto precedeu a aproximação unilateral de Washington com Havana, em abril do mesmo ano, com a permissão de viagens e do envio de remessas, assim como com a gestão de serviços de telecomunicações com a Ilha. Isso foi seguido pela proposta, em maio, de retomar negociações acerca da migração, interrompidas por Bush em 2003, e, em junho, pela histórica revogação da expulsão de Cuba da Organização dos Estados Americanos (OEA), com base na proposta de boa parte dos países da região.

O estreitamento com Cuba preparou um clima político receptivo para Obama na V Cúpula das Américas, que, sem grandes acordos políticos, ocorreu em abril de 2009, em Trinidad e Tobago. Na ocasião, o estadunidense exibiu seu estilo conciliador e anunciou sua intenção em buscar uma aliança de iguais, admitindo que, "embora os EUA tenham feito muito em favor da paz e da prosperidade no continente, por vezes também temos nos desengajado ou tratado de ditar nossas condições" (BARACK..., 2009). ${ }^{8}$ Na opinião de Abraham Lowenthal, a principal razão desse envolvimento precoce com a América Latina foi "a percepção da nova equipe de que, embora os países da região não representem problemas urgentes para os Estados Unidos, alguns deles, especialmente o México, são cada vez mais importantes para o futuro da América do Norte" (LOWENTHAL, 2011, p. 3).

Contudo, o entusiasmo foi efêmero. Imediatamente após a Cúpula, alguns eventos infelizes para o sentimento latino-americano trouxeram de volta a velha suspeita da natureza imperialista da política hemisférica dos Estados Unidos. O primeiro destes foi o anúncio do controvertido acordo para o uso estadunidense de sete bases militares em solo colombiano por dez anos, em troca de 40 milhões de dólares. Posteriormente invalidado pela Corte Constitucional da Colômbia, esse acordo reavivou velhos temores de intervencionismo militar na América do Sul, em particular na Venezuela e no Equador, e motivou 
a reação imediata dos governos do Cone Sul, através da União de Nações Sul-Americanas (Unasul).

Logo depois, veio o golpe de Estado em Honduras, contra Manuel Zelaya, no final de junho de 2009, no qual a diplomacia de Washington teve envolvimento ambíguo, inicialmente condenando o mesmo, para terminar lhe dando o aval a partir das eleições de transição do mês de novembro, na contramão da maioria dos países latino-americanos, que as qualificou de ilegítimas e nulas.

Como resultado, no final do primeiro ano de gestão, já era palpável a ausência absoluta de uma nova política hemisférica, o que nem mesmo a demorada designação de Arturo Valenzuela como responsável por Assuntos Hemisféricos no Departamento de Estado pode encobrir; mais precisamente, os eventos referidos foram dando suporte à ideia de uma continuidade fundamental no que diz respeito à negligência, à ineficácia e ao desinteresse, que haviam sido denunciados pelo próprio Obama em 2008.

Por conseguinte, as críticas surgiram não apenas por parte dos governos hostis aos Estados Unidos, como Cuba, Venezuela ou Bolívia, mas também por parte do Brasil e de outros setores da região. ${ }^{9} \mathrm{Na}$ própria América do Norte, essa ausência de uma política hemisférica foi denunciada tanto pela direita republicana - expressa pelo senador Jim DeMint - quanto por centros de opinião progressistas (LOWENTHAL, 2011, p. 11).

Um importante ponto que tem repercutido no clima hemisférico é o tema migratório, que, ainda que pertença à esfera doméstica dos Estados Unidos, tem natureza "interméstica” (ou seja, internacional e doméstica) e envolve de perto a região. Como mencionamos, Obama prometera, durante a campanha, avançar uma reforma migratória integral que regularizasse a situação de mais de 12 milhões de imigrantes latinos sem documento. No entanto, até agora, não se promoveu politicamente seu tratamento, tendo sido relegado frente à pre- 
mência dos desafios econômicos e à sua aposta na reforma do sistema de saúde. Ao contrário, em matéria de migração, houve um reforço da militarização da fronteira com o México e aumento do número total de deportados, passando de 369.221 em 2008 - último ano de Bush -, para 396.906 em 2011. ${ }^{10}$

Entre as promessas não cumpridas, deve-se apontar que não se determinou um enviado especial para o hemisfério, ao passo que, para o caso do conflito palestino-israelense, houve a nomeação de George Mitchell. A promessa de maior esforço diplomático sustentado, pautado em princípios e agressivo em escala regional não se realizou. Tampouco houve a expansão do serviço exterior, de tal forma que, entre 2009 e 2012, não houve embaixadores dos Estados Unidos na Venezuela, na Bolívia e no Equador. Ao passo que Obama visitou doze países europeus em seu primeiro mandato, apenas seis nações latino-americanas foram visitadas: México (em abril e agosto de 2009 e junho de 2012, para a Cúpula do G-20), Trinidad e Tobago (em abril de 2009, para a V Cúpula das Américas), Brasil, Chile e El Salvador (todos os três em março de 2011, ocasião do único giro oficial pela região) e Colômbia (em abril de 2012, para a VI Cúpula das Américas). Vale aduzir que o giro oficial de março de 2011, tendo como prioridade a busca de Washington pela expansão de oportunidades comerciais e pelo restabelecimento de vínculos políticos com Brasília e Santiago, deixou um rastro de insatisfação, fruto do início concomitante da intervenção militar na Líbia. José Piñeda, ex-ministro e irmão do presidente chileno, resumiu da seguinte forma a vista: “"Veni, vidi, vici' ('Vim, vi, venci') foi mensagem no Twitter de César a Roma depois de uma vitória. 'Veni, vidi e não disse nada' será a mensagem de hoje de Obama."

O desencanto regional também tem sido apoiado na continuidade da retórica estilo Guerra Fria, a respeito de países como Venezuela e seus parceiros na Aliança Bolivariana para as Américas (ALBA) (BARRETT et al., 2010). Nesse sentido, o governo democrata não 
logrou libertar-se de ineficazes categorias e posturas que dificultam sua aproximação com esses países. ${ }^{11}$

Por outro lado, mais um importante aspecto que permite a avaliação do grau de relevância atribuída à América Latina pela atual política externa estadunidense são as transferências monetárias oficiais, segundo o conceito de ajuda militar-policial e econômico-social. Conforme dito acima, Obama comprometeu-se durante sua campanha a aumentar essa ajuda, que já vinha em alta desde os anos de Bush. De acordo com dados disponibilizados pelo site Just The Facts, assim foi feito para o orçamento do ano fiscal de 2012, aumentando em $10 \%$ a ajuda militar (para 1,6 bilhão de dólares) e em 50\% a econômica (para 2,695 bilhões de dólares), em comparação com o ano anterior, alcançando, com isso, um pico total de 4,297 bilhões (ver Gráfico 1). ${ }^{12}$ No entanto, provavelmente por efeito da grande crise econômica e da crescente autoconsciência acerca da debilidade fiscal de Washington, desde então o orçamento de ajuda para a América Latina teve uma redução drástica, acumulada em 47\%, nos anos de 2011 , $2012{\text { e } 2013^{13}}^{13}$

Enquanto isso, a região, em seu conjunto, foi se distanciando cada vez mais de Washington, auferindo margens de autonomia, dando prosseguimento a instâncias subregionais que excluem os Estados Unidos e o Canadá - como a Unasul ou a Comunidade dos Estados Latino-Americanos e Caribenhos (CELAC) - e descartando com mais frequência os âmbitos compartilhados, como a OEA ou o Banco Interamericano de Desenvolvimento (BID). Ademais, vários países têm estreitado seus vínculos com atores extrarregionais que causam desconfiança na Casa Branca, como Rússia e Irã; e praticamente toda a região tem recebido com aprovação a ofensiva diplomática e econômica da China, reorientando seu comércio exterior e seu padrão de investimentos, em virtude da demanda e dos capitais oferecidos pelo gigante asiático. ${ }^{14}$ 
Yes We Can? A Política Externa de Obama para a América Latina: Da Decepção...

\section{Gráfico 1}

Total da Ajuda dos Estados Unidos a Países da América Latina, em Milhões de Dólares

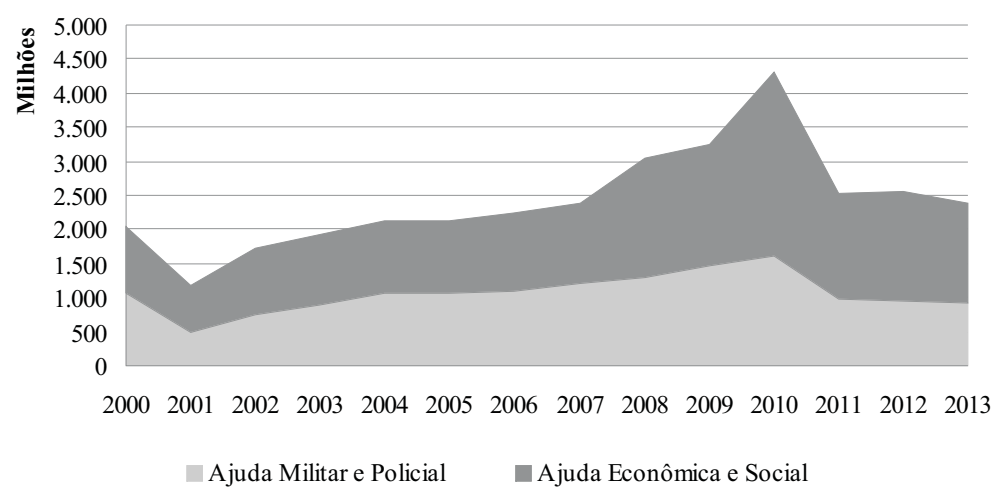

Fonte: Elaboração própria, com base no site Just The Facts. Disponível em: <http://justf.org>

Ambos os desdobramentos não têm passado despercebidos pela Casa Branca. Dessa forma, a visita de Hillary Clinton, em junho de 2010, ao Peru, Equador, Colômbia e Barbados, durante a qual esteve presente na $40^{\underline{a}}$ Assembleia Geral da OEA e teve um encontro com as autoridades à frente da Unasul, buscou precisamente respaldar o primeiro organismo perante a ascensão do segundo (BARRETT et al., 2010). A secretária de Estado também tem sido uma das principais vozes a expressar inquietude sobre o protagonismo crescente de potências extrarregionais no hemisfério. Nesse aspecto, suas declarações diante de funcionários de sua pasta, em maio de 2009, são bem eloquentes sobre o diagnóstico das altas esferas de Washington:

O que estamos fazendo não tem funcionado muito bem e, de fato, se observarmos os ganhos que o Irã está obtendo e que a China está obtendo, particularmente na América Latina, é muito preocupante. [...] Eles estão construindo laços econômicos e políticos muito fortes com muitos desses líderes. Tenho que dizer que acredito não ser de nosso interesse - no mundo 
multipolar de hoje, em que competimos por atenção e por relações com os russos, os iranianos e os chineses - dar as costas aos países do nosso próprio hemisfério (CLINTON..., 2009).

Como resultado final desse percurso de desencantos, a imagem de Obama na América Latina tem se deteriorado, despencando dos $62 \%$ de 2009 para 47\% em 2012, segundo pesquisa do Gallup publicada em abril de 2012. A queda foi dramática na maioria dos países pesquisados: no México, de $43 \%$ a 19\%; na Venezuela e na Bolívia, de $31 \%$ a $17 \%$; no Chile, de $60 \%$ a $25 \%$; no Uruguai, de $53 \%$ a $20 \%$; e, na Argentina, de $42 \%$ a $23 \%$ (LATINOAMÉRICA..., 2012).

Tudo isso tem aprofundado um importante abismo entre o bloco de países maiores da região e os Estados Unidos, o que se manifestou na VI Cúpula das Américas, ocorrida em abril de 2012, em Cartagena, Colômbia. Na ocasião, foram trazidos à discussão três grandes assuntos, ocultando o resto da agenda: a aceitação futura de Cuba na Cúpula, a legalização de algumas drogas - como medida de combate ao narcotráfico - e o apoio à Argentina em sua reivindicação de soberania sobre as Ilhas Malvinas. Sobre nenhum deles foi possível obter um acordo mínimo, fundamentalmente em razão da intransigência de Obama, que pareceu mais interessado em sua disputa eleitoral presidencial do que na oportunidade de um intercâmbio profícuo com os países de sua região (¿ESTADOS..., 2012). No caso de Cuba, apenas Estados Unidos e Canadá votaram pela manutenção da exclusão, ao passo que todos os demais 31 países participantes se manifestaram a favor de Cuba. Isso acabou por impedir a promulgação de uma declaração final do encontro, evidenciando a disfuncionalidade do espaço. Ainda mais relevante é o fato de os países da ALBA terem afirmado que, enquanto prosseguir a exclusão de Cuba, não voltarão a participar do evento - a rigor, Rafael Correa, do Equador, em protesto antecipado, sequer esteve presente na Cúpula -, postura que os países-membros do Mercado Comum do Sul (Mercosul) ameaçaram 
seguir. Caso venha a se confirmar a saída de vários desses Estados, a Cúpula das Américas e, por vinculação direta, a OEA poderão perder toda a legitimidade como instâncias de negociação hemisférica e acabar feridas fatalmente (SUVER, 2012).

Além disso, vale notar que a negativa quanto ao ingresso de Cuba evidencia os limites da mudança na política para a ilha, em particular, e para o hemisfério, como um todo, logo depois da positiva abertura unilateral ocorrida no início da gestão Obama. A maneira mais oportuna e, poder-se-ia dizer, mais realista para alterar o atual foco de Obama para a América Latina é a redefinição da política para a ilha, com característica mais madura e intelectualmente crível (BOULTINGHOUSE, 2012). O critério decisivo, nesse sentido, aos olhos dos governos da região continua sendo o fim do bloqueio que já dura mais de cinquenta anos e que responde a uma lógica macartista já anacrônica.

Como pano de fundo, é preciso dizer que Obama deixou passar, até o momento, a oportunidade de apresentar grandes iniciativas e implementar políticas para a região que possuam eixos renovados. Com efeito, "os pilares sobre os quais a administração dos Estados Unidos tem fixado as prioridades de sua agenda hemisférica carecem de resultados concretos e visíveis. Isso é interpretado por muitos como uma desconexão" (LOWENTHAL et al., 2011, p. vii). Entretanto, a metáfora de desconexão pode ser enganosa. A América Latina e os Estados Unidos seguem profundamente entrelaçados em suas interações políticas, econômicas e migratórias, sendo, portanto, mutuamente significativos. A Casa Branca sabe disso; como disse Obama durante sua estadia em Santiago:

A América Latina vai se tornar cada vez mais importante para os Estados Unidos, especialmente para nossa economia. O comércio entre Estados Unidos e a América Latina tem aumentado consideravelmente. Compramos seus 
produtos e serviços mais do que qualquer outro país e investimos nessa região mais do que qualquer outro país. Por exemplo, exportamos para a América Latina mais de três vezes o que exportamos para a China. Nossas exportações para essa região - que aumentam mais rápido que nossas exportações para o resto do mundo - em breve serão responsáveis por mais de 2 milhões de empregos nos Estados Unidos. Ou seja, quanto mais próspera for a América Latina, mais prósperos serão os Estados Unidos (OBAMA, 2011).

Mas o verdadeiro fracasso da administração inclui, ainda, não ter desmontado, e sim reforçado, duas lógicas herdadas da política hemisférica de Bush. A primeira lógica faz com que ainda prossigam: sua militarização, entendida como a primazia do Pentágono e de seu Comando Sul sobre o Departamento de Estado na tomada de decisões e ações concernentes a países da região (ISACSON, 2005), o que ficou evidente na crise em torno das bases colombianas; o aprofundamento do enfoque duro na luta contra o narcotráfico na América Central e no Caribe; ${ }^{15}$ a militarização da ajuda humanitária no Haiti; a manutenção da IV frota; a continuidade das Cúpulas dos Ministros de Defesa e de Segurança Pública das Américas; as sistemáticas reuniões de chefes do Exército, da Marinha e da Aeronáutica, coordenadas pela Junta Interamericana de Defesa (JID), assim como as diversas manobras militares interamericanas (como as denominadas Unita e Panamax), convocadas pelo Pentágono para amparo mal denominado Tratado Interamericano de Assistência Recíproca (TIAR) (SUÁREZ SALAZAR, 2011).

Além dessa lógica, há a construção de facto da fracassada Área de Livre Comércio das Américas (ALCA), por meio de tratados de livre-comércio bilaterais (RUSSELL, 2006, p. 53), nesse caso com a aprovação dos acordos com a Colômbia e o Panamá no fim de 2011. Recorde-se que Obama prometera em sua campanha presidencial re- 
ver o conteúdo desses tratados, a fim de eliminar suas assimetrias e observar as reivindicações de distintos setores sociais e sindicais potencialmente afetados. Mais ainda, a concretização desta ALCA de facto pode se consolidar no futuro, com o ingresso dos Estados Unidos no Acordo Estratégico Transpacífico de Associação Econômica (TPP, na sigla em inglês), que busca integrar comercialmente as economias do Pacífico americano com as asiáticas.

Em suma, essas duas lógicas correspondem ao tradicional viés pragmático de política externa e à manutenção do velho esquema da presunção hegemônica. Em sentido oposto caminha a retórica mais conciliatória e de aspecto colaborativo de Obama, colocando em evidência as contradições entre objetivos, valores e instrumentos da política de Washington para a região. Enquanto isso, a América Latina muda, a passos acelerados, sua velha fisionomia de pátio traseiro para a de uma nova e mais independente vizinhança.

\section{Lidando com os Autônomos: Venezuela, Brasil e Argentina}

Roberto Russell e Juan Gabriel Tokatlian (2000, p. 3-4) explicam que a autonomia é um conceito que faz referência à capacidade e à condição de um Estado-nação para articular e alcançar metas políticas de forma independente. ${ }^{16} \mathrm{Na}$ dimensão especificamente externa, caracteriza-se pela disposição a tomar decisões em matéria internacional, sem interferências nem constrangimentos de atores externos, e a controlar processos ou acontecimentos que se produzem para além das fronteiras de seu Estado. Essa autonomia internacional depende, portanto, das próprias capacidades dos Estados, assim como das condições que imperam em nível regional/mundial.

A mudança de fisionomia da América Latina, mencionada acima, responde tanto à atenção global dos Estados Unidos em suas guerras 
no Oriente Médio e na Ásia Central durante já mais de uma década, quanto ao próprio desempenho, em matéria econômica, de muitos países da região. Nesse último ponto, os chamados governos pós-neoliberais têm consolidado uma confiança e uma atitude autônoma de assegurar seus vínculos mútuos, por meio do impulso de espaços de integração e/ou coordenação que excluem Washington e questionam o velho esquema panamericanista. Dessa forma, a política externa estadunidense, além de fragmentada em sua dimensão doméstica (LOWENTHAL, 2007), tem se deparado ao longo da última década, e em comparação com os anos 1990, com um número menor de interlocutores governamentais afins a suas iniciativas.

Três dos principais Estados-nação que no período recente se manifestaram, de diferentes formas, abertamente como autônomos em relação aos desígnios de Washington são Venezuela, Brasil e Argentina. A seguir, apresentam-se as principais características das relações bilaterais de cada um desses países com a potência estadunidense.

\section{Venezuela}

O caso da Venezuela apresenta uma relação bilateral bem particular, marcada por uma postura política autônoma de confrontação por parte de Caracas, coexistindo de maneira paradoxal com uma estreita dependência econômica em relação à superpotência do Norte. De fato, poder-se-ia falar de uma relação bilateral dual, que transita por dois cursos distintos: por um lado, o político-diplomático; por outro, o econômico-petroleiro. Este matrimônio incômodo (MCCOY, 2011, p. 69) explica as contradições entre a dura retórica e a realidade de florescimento dos intercâmbios comerciais. Assim, o governo dos Estados Unidos vem sendo considerado por Miraflores como "a fonte de todos os males mundiais", por seu caráter imperial; em concomitância, consolida-se como o principal parceiro comercial da Venezuela e o primeiro destino de suas exportações (ver Gráfico 2). Entre 2002 e 2008, enquanto o vínculo político praticamente desabou, o 
Yes We Can? A Política Externa de Obama para a América Latina: Da Decepção...

\section{Gráfico 2}

Exportações da Venezuela aos seus Principais Países de Destino, 2007-2010 (FOB US\$)

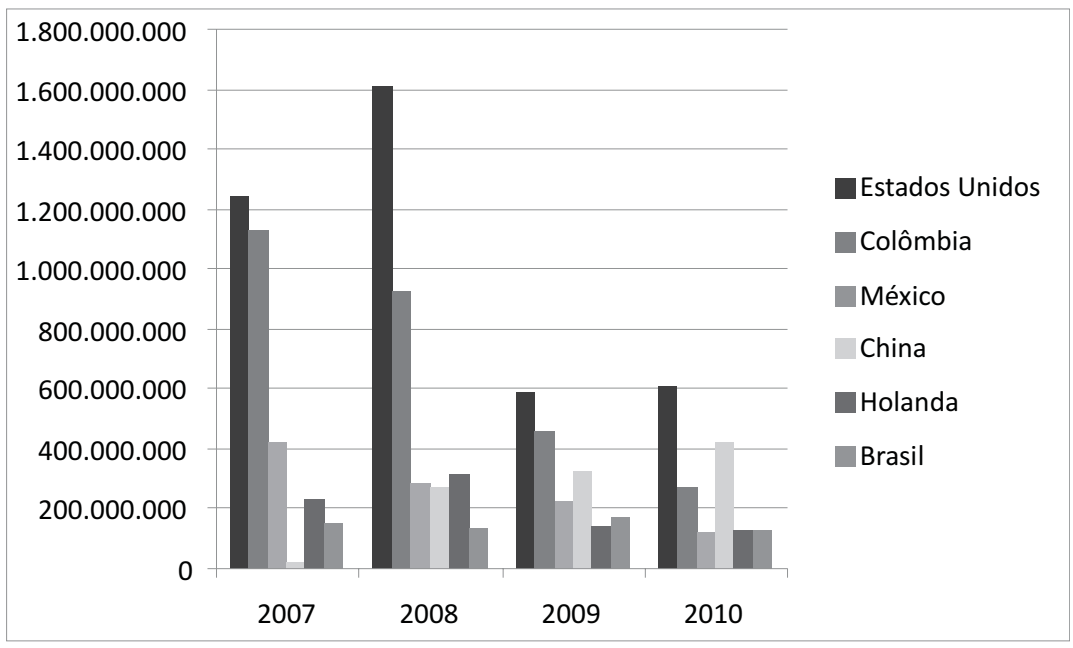

Fonte: Elaboração própria, com base no Instituto Nacional de Estadísticas (INE) da Venezuela, 2012. Disponivel em: <http://www.ine.gov.ve/>.

comércio total entre essas nações foi alavancado de 19 bilhões para 64 bilhões de dólares.

O petróleo é o eixo da chamada dualidade. Em 2009, os Estados Unidos compraram $55 \%$ dos envios totais de petróleo da Venezuela ao exterior, fluxo que se interrompeu na última década apenas durante a greve petroleira de 2002-2003. De acordo com a própria embaixada da Venezuela nos Estados Unidos:

Em 2010, os Estados Unidos importaram da Venezuela 32,7 bilhões de dólares em bens, a maior parte proveniente do setor petroleiro. A nação venezuelana é um dos maiores, mais próximos e consistentes fornecedores de petróleo dos Estados Unidos no mundo. A companhia estatal Petróleos de Venezuela (PDVSA)é 
dona da Citgo Petroleum Corporation, empresa situada nos Estados Unidos, responsável por três refinarias, as quais produzem 117 milhões de barris de gasolina por ano, vendidos nos 13 mil postos em todo o país (EMBAJADA DE LA REPÚBLICA BOLIVARIANA DE VENEZUELA EN ESTADOS UNIDOS, 2011). ${ }^{17}$

Em contrapartida, o eixo explicativo das confrontações e diferenças manifestadas durante a última década entre Washington e Caracas reside no abismo político que gerou, por um lado, o aprofundamento do unilateralismo estadunidense durante a administração Bush e, em especial, o envolvimento na tentativa de golpe de Estado, em abril, contra o presidente Hugo Chávez e, por outro lado, o forte ativismo revisionista da política externa bolivariana, calcado, por sua vez, na diplomacia petroleira (SERBIN, 2006). Os objetivos desta última têm se concentrado na contraposição à hegemonia global e regional dos Estados Unidos, no impulso à integração latino-americana e à construção de um sistema internacional multipolar e na conversão do país em uma potência, com base em seu poderio energético. Sob esse prisma, a cooperação bilateral arrefeceu-se, começando já com a suspensão de acordos na área de luta contra as drogas e de assistência naval, enquanto as escaladas verbais se elevaram, alcançando o pico com as referências de Chávez ao rastro de enxofre deixado pelo presidente Bush no discurso na Assembleia Geral da ONU, em 2006.

Nesse sentido, a chegada de Obama à Casa Branca gerou calorosas esperanças de uma recomposição da relação bilateral, que partiam de sua predisposição ao diálogo com seu par venezuelano. O próprio Chávez disse na época que "a eleição histórica de um afrodescendente [é sintoma de que] a mudança de era que se gestou a partir do sul da América pode estar batendo à porta" dos Estados Unidos. Os gestos de distensão culminaram no episódio em que Chávez presenteou Obama com o clássico Las venas abiertas de América Latina (As veias abertas da América Latina), do escritor uruguaio Eduardo Galea- 
no, durante a V Cúpula das Américas. No entanto, o acordo referente às bases na Colômbia e o golpe contra Zelaya, em Honduras, rapidamente reativaram as diferenças. No primeiro caso, o governo venezuelano foi o principal crítico da iniciativa, a qual considerou um símbolo da continuidade do imperialismo ianque na região. No segundo caso, por sua vez, os setores republicanos encorajaram as divisões bilaterais, ao criticar a Casa Branca por ceder ante a ofensiva chavista na América Central e, com isso, impingir a mudança de atitude que levou Washington a aceitar as eleições hondurenhas no final de 2009. Dessa forma, a relação bilateral voltou à sua normalidade de confrontação, de tal forma que, em meio ao colapso da Cúpula de Copenhague, Chávez disse: "Todavia, sigo a cheirar enxofre por aqui."

Além do ocorrido nesses eventos, as diferenças políticas foram acentuadas também pelo aprofundamento do relacionamento autônomo da Venezuela com países como a Rússia, a China, Cuba, a Líbia de Kadafi e, fundamentalmente, o Irã, no esforço de contrabalançar a influência estadunidense. Os acordos alcançados nesses últimos anos com esses países disseram respeito a petróleo, armas e investimentos produtivos conjuntos, e levantaram suspeita em Washington em relação ao tráfico de armas para as Forças Armadas Revolucionárias da Colômbia (FARC), às corridas armamentistas na região, ao incentivo à proliferação nuclear e ao fomento do terrorismo.

Com isso, a administração Obama parece ter deixado escapar a oportunidade de reestruturar a relação bilateral com a Venezuela, em razão de suas próprias incapacidades, das resistências atávicas domésticas e da continuidade da conduta bolivariana de confrontação e de autonomia.

\section{Brasil}

O Brasil, por sua vez, converteu-se no século XXI em uma potência em franca ascensão e em um eventual parceiro estratégico dos Esta- 
dos Unidos. Para Washington, o governo de Brasília é não apenas um dos principais interlocutores regionais em matéria de segurança, democracia, desenvolvimento e comércio hemisférico, como também uma contraparte para impulsionar, de forma conjunta, temas globais, como a estabilidade financeira, a mudança climática e a reforma de instituições multilaterais (O’NEIL, 2010, p. 3).

No entanto, na perspectiva brasileira, a prioridade em matéria de inserção internacional continua sendo a América do Sul. Nesta, o Brasil tem apostado na liderança de novos processos de articulação regional e de integração que sirvam de base para potencializar a competitividade de sua economia e ampliar a margem de autonomia política nas negociações internacionais.

Nesse contexto, a relação bilateral entre Brasil e Estados Unidos recebeu um impulso durante o segundo mandato de Bush, com suas visitas ao país sul-americano em 2005 e 2007, quando celebrou, com Lula, acordos nas áreas de educação, ciência e tecnologia e, em especial, biocombustíveis. Ambos os governos selaram, então, o que ficou conhecido como a Aliança do Etanol, mas que, em termos práticos, implicou em uma diminuição das barreiras tarifárias à importação do etanol brasileiro por parte dos Estados Unidos.

Apesar da aparente boa relação entre Bush e Lula, dos encontros governamentais de mais alto nível e desses acordos, a macrorrelação tem permanecido estagnada, embora respeitosa (DE CASTRO NEVES; SPEKTOR, 2011, p. 43). A chegada do presidente Obama não alterou esse quadro. De fato, a dinâmica bilateral em 2009 foi afetada pela política doméstica estadunidense: congressistas republicanos conseguiram bloquear por quase um ano a nomeação de Thomas Shannon como embaixador no Brasil. A isso, somaram-se as mesmas desavenças já mencionadas que dissiparam na região a expectativa inicial depositada em Obama. 
Um capítulo bilateral particularmente controverso ocorreu na primeira metade de 2010. Por expresso pedido de Obama a Lula, Brasil e Turquia envolveram-se como intermediários e lograram êxito em um acordo para a saída de $1.200 \mathrm{~kg}$ de urânio levemente enriquecido do Irã, em troca de combustível para o reator experimental de Teerã (OBAMA'S ..., 2010). O conflito em torno do programa nuclear iraniano parecia, assim, alcançar um princípio de resolução. Entretanto, a diplomacia estadunidense, assim que inteirada do acordo, optou por retirar seu apoio inicial, gerando forte proibição e o consequente esfriamento das relações com o Itamaraty.

Por outro lado, uma modificação relevante na relação bilateral durante esses anos foi o fato de os Estados Unidos terem deixado o posto de principal parceiro comercial do Brasil, agora ocupado pela China. A mudança de posições ocorreu em abril de 2009, depois de oitenta anos de predomínio estadunidense ininterrupto. O Gráfico 3 mostra o veloz e tendencial crescimento das trocas com o país asiático - alcançando 77 bilhões de dólares em 2011 - em comparação com os Estados Unidos - com 60 bilhões no mesmo ano. Sendo a segunda economia do hemisfério e a principal da América Latina, o Brasil é, com isso, um exemplo da perda estrutural de lugar que Washington está sofrendo por toda a região, diante do gigante asiático.

A visita de Obama ao Brasil, em março de 2011, teve, entre seus principais objetivos, exatamente a tentativa de frear o êxito chinês, mediante uma maior imbricação econômica, e de recompor o diálogo diplomático, depois do desencontro causado pelo tema do Irã. Contudo, a aproximação nas áreas de comércio e de investimentos foi mais simbólica, expressando-se apenas em roteiros para futuras negociações. Não houve avanços nos pontos que haviam elevado as relações a um novo nível - as disputas comerciais por aço e bens agrícolas -, tampouco no plano político, com relação ao velho desejo do Brasil de ter um assento permanente no Conselho de Segurança das Nações Unidas. Pior ainda, o início da intervenção na Líbia, autorizada por 


\section{Gráfico 3}

Comércio Total do Brasil com China e Estados Unidos, 2007-2011 (em Milhões de Dólares)

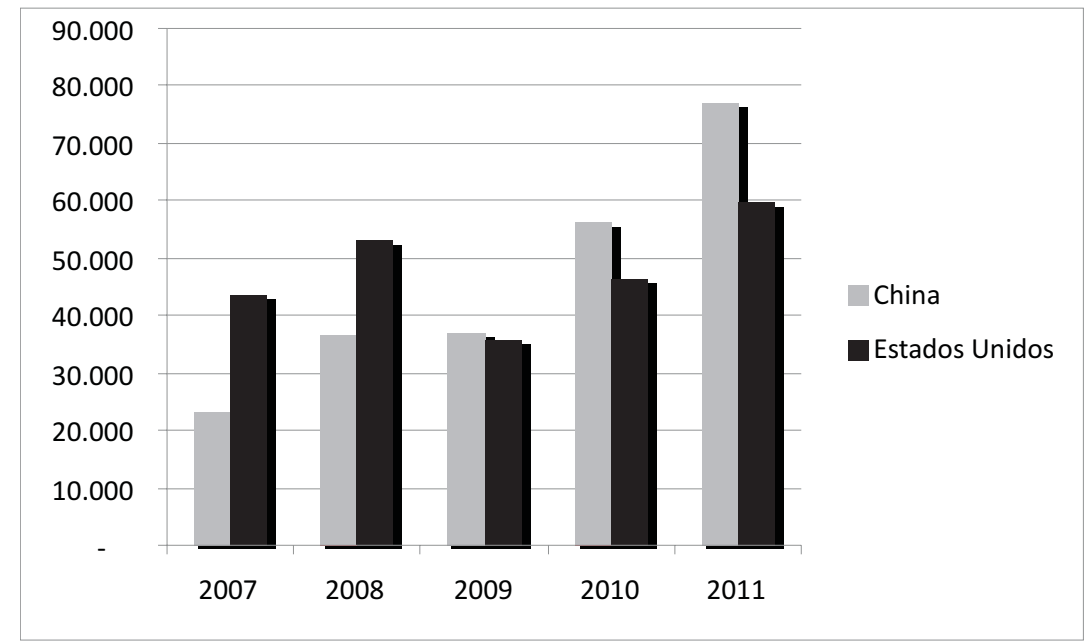

Fonte: Elaboração própria, com base na Associação de Comércio Exterior do Brasil (2012).

Obama quando estava no solo brasileiro, chocou-se com a recusa de Brasília a apoiar a resolução para o uso da força. Depois desses episódios, não houve ações significativas de abertura da parte de Washington que tendam a modificar o distanciamento.

\section{Argentina}

No que concerne à Argentina, nos últimos anos, tem se conservado o padrão de relação bilateral inaugurado em 2003, pelo qual Buenos Aires mantém uma autonomia distante de Washington, na qual a colaboração coexiste com desacordos de menor expressão, mas que se diferencia do alinhamento irrestrito dos governos de Carlos Menem e do choque ideologizado ao estilo da Venezuela (TUSSIE, 2004).

Nesse sentido, a chegada de Barack Obama à Casa Branca foi interpretada pelo governo nacional como uma oportunidade para que a 
Argentina gerasse uma relação mais fluida e construísse uma agenda positiva, a partir da predisposição ao diálogo e da vontade de maior entendimento por parte do novo presidente. Os temas da agenda, por parte de Washington, não eram novos: exigir que o governo argentino ressarça os portadores de títulos que rejeitaram o calote da dívida nacional em 2005; assegurar um cenário institucional e político que não prejudique os investimentos norte-americanos; cobrar o pagamento do governo argentino das sentenças contrárias dadas no tribunal do Centro Internacional para Arbitragem de Disputas sobre Investimentos (CIADI); e demandar a renegociação da dívida com o Clube de Paris. Do lado da Argentina, as prioridades continuaram vinculadas à necessidade de que o mercado estadunidense se abra a produtos estrangeiros e à chegada de investimentos e de financiamento. No que diz respeito às coincidências entre os dois governos, as principais registraram-se nos temas de não proliferação nuclear, especialmente com a participação argentina na Agência Internacional de Energia Atômica (AIEA) e em outros fóruns, como a Cúpula de Segurança Nuclear, realizada em abril de 2010, em Washington.

No entanto, as ilusões de mudança também se perderam diante dos eventos continentais e o baixo desempenho da administração Obama. Cristina Kirchner assegurou que o presidente dos Estados Unidos "não correspondeu às expectativas" durante a Cúpula da Unidade da América Latina e do Caribe, em fevereiro de 2010, quando se criou a CELAC.

Desde o começo de 2011, a relação bilateral tem sido abalada por controvérsias relativamente menores. Por exemplo, houve um mal-estar em Buenos Aires quando veio ao conhecimento que Obama visitaria somente Brasil e Chile em seu giro presidencial pela América do Sul e, posteriormente, com o escândalo do avião militar estadunidense que aterrissou em Ezeiza, transportando material bélico e de inteligência não declarado. Diante desse clima, tentou-se uma aproximação na ocasião da VI Cúpula do G-20, em Cannes (nos dias 3 e 4 
de novembro de 2011), quando Cristina Kirchner destacou o benefício para os Estados Unidos da relação comercial, dado o superávit de 4,7 bilhões a ser favor, em 2011. ${ }^{18}$

No entanto, em março de 2012, prosseguiram as diferenças, dessa vez na área econômico-comercial, com a suspensão da Argentina do Sistema Geral de Preferências (SGP) - no qual se eximem de tarifas as importações de milhares de produtos de países em desenvolvimento -, a apresentação de queixas na Organização Mundial do Comércio (OMC), referidas ao protecionismo argentino, e os votos negativos de Washington para os créditos que Buenos Aires negociava no BID e no Banco Mundial.

Em conjunto, esses eventos são indicativos de que a administração Obama tem dado continuidade à sua postura de repreensão e punição ao país do Sul, evidenciada especialmente no bloqueio do acesso argentino ao poder de investimento transnacional, como reação à sua desobediência na questão financeira e comercial (MIRANDA, 2012, p. 1). É fundamental entender essa conduta a partir do nível de análise da política doméstica estadunidense, em especial seu contexto eleitoral. O endurecimento das posições tem pretendido angariar os votos de grupos próximos dos republicanos, das corporações empresariais e dos setores defensores da globalização, que entendem a arquitetura institucional internacional como um instrumento de desenlace das medidas implementadas pelos países em defesa de seus interesses nacionais. Dessa forma, as relações internacionais do país com nações intermediárias vêm sendo presa fácil dos avatares e dos atores que dominam o jogo político estadunidense.

\section{Yes we can? Expectativas não Correspondidas e Autonomia Crescente}

Ao fim de seu primeiro mandato na Casa Branca, fica evidente que o entusiasmo internacional inicial que suscitou Barack Obama se con- 
verteu em um claro desencanto acerca de sua gestão, nítido na erosão de sua imagem, mostrada em várias pesquisas.

De onde vêm as razões dessa frustração? Obama traiu as promessas? Eram, estas, implausíveis? Os países da região depositaram esperanças excessivas ou infundadas? Parte da explicação para essas perguntas reside no reconhecimento de que, como apontamos, Obama despertou expectativas muito altas de mudança e recomposição das relações hemisféricas e da política internacional, em virtude da singularidade histórica de sua ascensão política - tanto dentro quanto fora dos Estados Unidos -, potencializada com êxito por meio do marketing eleitoral, mas também pelo simples efeito de ter sucedido um dos presidentes mais impopulares da história dos Estados Unidos.

O próprio Obama se encarregou de alimentar as expectativas, prometendo, de maneira geral, um relançamento das relações hemisféricas, a new Alliance for the Americas (uma nova Aliança para as Américas), com base no critério de não mais ditar os termos para a região, e sim escutá-la e trabalhar junto a ela; e, de maneira específica, uma série de compromissos, condensada em seu discurso "Renewing U.S. leadership..." (Renovando a liderança dos EUA), de 2008, entre os quais se destacam: renovado esforço diplomático em nível regional, reforma migratória, maiores níveis de transferências no conceito de ajuda, aproximação com Cuba e diálogo sem precondições com países como a Venezuela.

Alguns desses compromissos são velhas reivindicações da região, cuja possibilidade de realização vem se ampliando nas últimas décadas. É o caso da desejada normalização das relações com Havana, bloqueada por anacrônicos esquemas ideológicos da Guerra Fria e pela conduta do cada vez menos poderoso lobby cubano-estadunidense. Com uma liderança ativa e o capital político em seu favor, como ensina a reforma da saúde, presumimos que a administração Obama não teria grandes obstáculos em moldar um clima de ideias 
doméstico favorável para o fim do embargo a Cuba ou para impulsionar a aprovação de uma reforma migratória profunda. Por isso, fica nítido que o critério tático de não abrir novas frentes de conflito e a falta de vocação real têm mantido a América Latina fora do radar e cada vez mais distante.

Tendo em vista todos esses antecedentes e promessas, argumentamos que o aumento de expectativas registrado ao sul do Rio Bravo foi justificado. Os diversos governos e sociedades latino-americanos podem ter pecado por ingenuidade, a respeito das margens de transformação e manobra que caracterizam o desempenho de uma potência com os Estados Unidos, porém a oportunidade apresentada e as mensagens de mudança recebidas induziram a tais expectativas. Como expressara a presidente argentina Cristina Kirchner em 2010, embora "ninguém esperasse um príncipe em um cavalo branco", existia, de fato, a expectativa de "um realismo sério, que conhecesse o que havia passado na América Latina e as necessidades que a América Latina tinha e tem de uma política diferente para a região" (CRISTINA..., 2010). Nesse sentido, Washington não tem aproveitado uma importante oportunidade de recompor sua imagem e seus interesses hemisféricos.

Ao desencanto pelas expectativas não correspondidas e pela negligência, soma-se o desencanto pela continuidade da presunção hegemônica dos Estados Unidos diante da América Latina, evidenciada no prosseguimento da militarização da política hemisférica, no apoio ao golpe de Estado em Honduras e nos novos acordos bilaterais de livre-comércio.

No entanto, apesar disso tudo, a região, como um todo, está mudando sua fisionomia de pátio traseiro para a de uma vizinhança crescentemente autônoma. Em especial, os governos pós-neoliberais da região vinculam-se cada vez mais com potências extrarregionais e apostam na integração econômica e na coordenação política em espaços como 
a Unasul e a CELAC, de onde os Estados Unidos estão excluídos. Eles ensaiam, ademais, variados graus de autonomia bilateral com Washington: uma delas mais próxima - com base na mútua dependência petroleira -, porém conflituosa, como a da Venezuela; outra, intermediária, sustentada pelas capacidades e pela liderança regional do Brasil, com seus status de potência em ascensão; e, por último, uma autonomia com grau distante, dado o menor peso estratégico relativo da Argentina e produto do arrefecimento do vínculo, que se seguiu ao fim da política de alinhamento irrestrito dos anos 1990. A segunda parte deste artigo mostrou que, nesses três casos, a administração Obama tem se mostrado incapaz de refundar a relação bilateral e estreitar a cooperação, tornando-se presa da inércia burocrática e do jogo doméstico de setores duros.

Para concluir, consideramos que, nos níveis global, hemisférico e bilateral, Obama tem preferido moldar muitos de seus anseios de mudança aos imperativos e interesses político-econômico-estratégicos que emanam da condição de superpotência dos Estados Unidos. Buscando dotar tal acomodação de lógica e justificativa, quando laureado com o Prêmio Nobel da Paz, argumentou em seu discurso:

Como chefe de Estado, enfrento o mundo como ele é, e não posso ficar impassível diante das ameaças ao povo estadunidense. Para não restar dúvidas: o mal de fato existe no mundo. Um movimento não violento não poderia ter detido os exércitos de Hitler. Negociações não podem convencer os líderes da Al Qaeda a baixar suas armas. Dizer que a força pode, por vezes, ser necessária não é um chamado ao cinismo - é o reconhecimento da história, das imperfeições do homem e dos limites da razão (OBAMA, 2009).

Se essas palavras oferecem alguma virtude, a principal é refletir, como poucas o fazem, a atual tensão manifesta entre moralismo e 
pragmatismo que caracteriza a política externa da administração de Obama, em que os objetivos parecem ter o primado sobre os princípios, recordando-nos, dessa forma, de que a automoderação é uma virtude demasiado onerosa para uma potência ainda hegemônica.

\section{Notas}

1. Uma pesquisa realizada em meados de 2007 pelo Pew Research Center mostrou que, na Argentina, na Bolívia, no Brasil, no Chile, no Peru e na Venezuela, a desconfiança em relação ao presidente texano era tão alta que chegava até mesmo a superar, em alguns desses países, a rejeição a Osama Bin Laden.

2. Este conceito, elaborado por Joseph Nye Jr. e Suzanne Nossel, refere-se a "uma abordagem que enfatiza a necessidade de forte aparato militar, mas que também investe pesadamente em alianças, parcerias e instituições em todos os níveis, a fim de expandir a influência americana e estabelecer a legitimidade de sua ação" (ARMITAGE; NYE, 2007, p. 7).

3. Essas iniciativas foram legitimadas pela entrega do Prêmio Nobel da Paz em outubro de 2009.

4. Não obstante a nova retórica da administração Obama e das dificuldades provenientes da crise econômica iniciada em 2008, o gasto militar não parou de crescer de 1999 (280 bilhões de dólares) até 2011 (711 bilhões), segundo o Stockholm International Peace Research Institute (SIPRI). Disponível em: $<$ http://www.sipri.org/>.

5. "A ideia de que os Estados Unidos possuem o direito de insistir na solidariedade - para não dizer na subordinação - política, ideológica, diplomática e econômica de todo o Hemisfério Ocidental" (LOWENTHAL, 2007).

6. Explica Leyvi Castro Martínez (2012, p. 209) que os "Estados Unidos elegeram em 2008 seu primeiro presidente afro-americano, Barack Obama, [...] e, graças a isso, este representou uma fórmula de esperança e mudança, apresentado com um ideário baseado em princípios de igualdade. Foi a personalidade de Barack Obama, em si mesma, que foi comercializada em livros, canções, capas de revista, o que converteu em 'produto' sua pessoa, com o glamour do tapete vermelho de um programa de televisão; o resultado foi ganhar a Presidência de seu país. Barack Obama é, sem dúvida, não apenas o melhor exemplo dos Esta- 


\section{Yes We Can? A Política Externa de Obama para a América Latina: Da Decepção...}

dos Unidos, como também, em nível internacional, do que a internet, o correio eletrônico, os celulares, os blogs etc. podem fazer para angariar a empatia das pessoas e angaria adeptos".

7. Na Argentina, o chanceler Jorge Taiana disse que a vitória de Obama "traz uma mensagem de esperança para o mundo" e encerra uma etapa "dominada pelo neoliberalismo". Na Venezuela, Chávez sustentou que "a eleição histórica de um afrodescendente [é sintoma de que] a mudança de era que se gestou a partir do sul da América pode estar batendo à porta" dos Estados Unidos. Na Bolívia, Evo Morales reconheceu o caráter histórico da vitória e pregou a melhora das relações bilaterais. No Brasil, o ministro Celso Amorim antecipou uma distensão dos vínculos da América Latina com os casos de Cuba e Venezuela e até mesmo se animou a traçar um paralelo com a eleição de Luiz Inácio Lula da Silva: "No caso de Lula, a esperança venceu o medo. No caso de Obama, a esperança venceu o preconceito" (EN AMÉRICA..., 2008).

8. Já em agosto de 2009, uma pesquisa do Pew Research Center demonstrava que, em apenas sete meses, a imagem de Washington havia recuperado os níveis atingidos antes da chegada de Bush. Com isso, a confiança nos Estados Unidos cresceu entre seus aliados tradicionais (Grã-Bretanha, França, Alemanha, Espanha, Canadá, Japão e Coreia do Sul), assim como aumentou significativamente em países latino-americanos, como Brasil, Argentina e México. Contudo, essa pesquisa também demonstrou que o ceticismo com relação à concretude de mudanças reais era muito alto.

9. Por exemplo, no caso da intervenção humanitária no Haiti, em decorrência do terremoto que assolou Porto Príncipe no começo de 2010, o esforço de resgate e reconstrução liderado por Washington foi alvo de importantes críticas. Enquanto Obama afirmava que, "em tempos de tragédia, os Estados Unidos dão um passo à frente e ajudam. Isto é o que somos. Isto é o que fazemos" (OBAMA, 2010, p. 24), os comandantes da Missão das Nações Unidas para a Estabilização do Haiti (MINUSTAH), assim como vários governos, queixaram-se do modo militarizado da assistência norte-americana. Foi o ministro de Cooperação da França, Alain Joyandet, quem sintetizou as colocações: "Trata-se de ajudar o Haiti, não de ocupá-lo" (apud SUOZZI, 2010).

10. Em 2012, o número parcial é de 366.292 , somando um total de quase 1.600.000 imigrantes deportados, a maioria latinos, nos quatro anos de governo democrata. Dados disponíveis em: <http://www.ice.gov/doclib/about/offices/ ero/pdf/ero-removals1.pdf>.

11. São um bom exemplo, nesse aspecto, as palavras do próprio Arturo Valenzuela (2011): "Como coletivo, devemos ser claros e proativos na hora de abordar os riscos de nossa agenda comum, que incluem as tentativas de ampliar o go- 
verno majoritário e populista, em detrimento dos direitos fundamentais das minorias e do governo democrático baseado em diálogo e consenso dentro do Estado de direito. E, embora felicitemos os líderes populares que optaram por abandonar o cargo em conformidade com as instituições de governo democrático, em vez de promover mudanças constitucionais para permanecerem no poder, lamentamos que a tendência oposta tenha se arraigado em vários países."

12. Esse forte aumento na ajuda econômica e social no ano de 2010 se explica, em grande medida, pelo aumento nos fundos destinados ao Haiti (1,135 bilhão de dólares, $42 \%$ do total), depois do terremoto ocorrido no começo daquele ano.

13. A marca progressista de Obama, em todo caso, subjaz a priorização da ajuda econômico-social (62\% do total) em relação à ajuda militar-policial (38\%), ao contrário do que vigia no período republicano (com média de $53 \%$ para a primeira, e $47 \%$ para a segunda). Isso não apaga o fato de que a Casa Branca está enfraquecendo de todas as formas uma de suas mais importantes alavancas de influência hemisférica.

14. A irrupção recente da China na América Latina levanta questionamentos acerca da eventual reação dos Estados Unidos, ante a deterioração de sua influência naquilo que historicamente têm considerado como seu "pátio traseiro". Trata-se de um cenário que, desde o início do século XXI, se segue com atenção nos think tanks de pensamento estratégico em Washington. Nesse ponto, distinguem-se ao menos duas posições: uma delas é a dos tomadores de decisão estadunidenses mais temerosos, que entendem a nova presença chinesa na região como um movimento inicial de um expansionismo em grande escala por parte de Pequim, destinado a desafiá-los em seu próprio hemisfério; a outra perspectiva, mais benigna, percebe os crescentes vínculos como uma oportunidade, não como uma ameaça, e como uma manifestação natural das necessidades energéticas e de recursos do país asiático, sem metas explícitas de choque com a superpotência (ROETT; PAZ, 2008, p. 1).

15. Uma particular consternação foi causada nos grupos defensores dos direitos humanos com o uso de fuzileiros navais na Guatemala - na operação Hammer - para tarefas de interdição do tráfico de drogas, na segunda metade de 2012. Deve-se recordar que, em março deste ano, ocorreu um incidente no povoado de Ahuas, localizado na Costa dos Mosquitos, em Honduras, quando um helicóptero norte-americano da Agência Antidrogas dos Estados Unidos (DEA, na sigla em inglês) abriu fogo contra uma canoa, sob a suspeita de que ela estaria contrabandeando narcóticos, assassinando duas mulheres grávidas e duas crianças, todas inocentes.

16. Esta seria, segundo os autores, uma das três formas de se entender a noção de autonomia nas Relações Internacionais. As duas outras formas definem a au- 


\section{Yes We Can? A Política Externa de Obama para a América Latina: Da Decepção...}

tonomia: a) como um dos dois princípios (o outro sendo a territorialidade) do modelo westfaliano; e b) como um dos interesses nacionais objetivos dos Estados (junto com a sobrevivência e o bem-estar econômico).

17. A isso, deve-se somar a continuação de importantes operações em solo venezuelano e a "boa relação" extraoficial de empresas como a Chevron com o governo bolivariano - o mesmo não ocorre com a Exxon, com a qual as disputas atingiram instâncias arbitrais internacionais, após a nacionalização de parte de seus ativos no projeto Cerro Negro.

18. Recorde-se, ainda, que, "com mais de quinhentas empresas radicadas no país e [...] um investimento de 12 bilhões de dólares" (UN ENCUENTRO..., 2011), os Estados Unidos são o investidor estrangeiro mais importante na Argentina, depois da Espanha.

\section{Referências Bibliográficas}

ARMITAGE, R.; NYE, J. CSIS Commission on smart power: a smarter, more secure America. Washington: Center for Strategic and International Studies, 2007. Disponível em: <http://csis.org/files/media/csis/pubs/071106_csissmartpowerreport.pdf>. Acesso em: 7 mai. 2012.

ASSOCIAÇÃO DE COMÉRCIO EXTERIOR DO BRASIL. Radiografia do Comércio Exterior Brasileiro: passado, presente e futuro. Rio de Janeiro, 15 jan. 2012. Disponível em: <htttp://www.aeb.org.br/userfiles/file/AEB\% 20-\%20Radiografia\%20Com\%C3\%A9rcio\%20Exterior\%20Brasil.pdf $>$. Acesso em: 13 jun. 2012.

BARACK Obama prometió una nueva relación con el continente americano. EI Comercio.pe, 18 abr. 2009. Disponível em: <http://elcomercio.pe/mundo/ 274744/noticia-barack-obama-prometio-nueva-relacion-continente-americano>. Acesso em: 22 abr. 2012.

BARRETT, A.; DEFEO, C.; LLOYD, S. Hillary Clinton visits Latin America: a renewed opportunity for regional cooperation or an intensification of the kind of neo-Cold War rhetoric that has categorized U.S Latin American policy to date? 
Council on Hemispheric Affairs, jun. 2010. Disponível em: $<$ http://www.coha.org/hillary-clinton-visits-latin-america-a-renewed-opportunity-for-regional-cooperation-or-an-intensification-of-thekind-of-neo\%E2\%80\%93cold-war-rhetoric-that-has-categorized-u-s-latinamerican-policy-t/>. Acesso em: 8 mai. 2012.

BOULTINGHOUSE, T. For Obama, four more years requires a willingness to look south. Council on Hemispheric Affairs, 7 nov. 2012. Disponível em: $<$ http://www.coha.org/for-obama-four-more-years-requires-a-willingnessto-look-south/>. Acesso em: 7 nov. 2012.

CASTRO MARTÍNEZ, L. El marketing político en Estados Unidos: el caso Obama. Norteamérica, ano 7, n. 1, jan.-jun. 2012.

CLINTON warns of Iranian, Chinese gains in Latin America. CNNPolitics.com, $1^{\circ}$ mai. 2009. Disponível em: <http://edition.cnn.com/2009/ POLITICS/05/01/clinton.latin.america/>. Acesso em: 10 jun. 2012.

CRISTINA: "Nadie esperaba que Obama fuera un príncipe en un corcel blanco". La Nación, 25 fev. 2010. Disponível em: <http://www.lanacion.com.ar/ 1237153-cristina-nadie-esperaba-que-obama-fuera-un-principe-en-un-corcelblanco>. Acesso em: 6 nov. 2012.

DE CASTRO NEVES, J.; SPEKTOR, M. Obama and Brazil. In: LOWENTHAL, A.; PICCONE, T.; WHITEHEAD, L. (Ed.). Shifting the balance: Obamas and the Americas. Washington D.C.: The Brookings Institution, 2011. p. 43-54.

EMBAJADA DE LA REPÚBLICA BOLIVARIANA DE VENEZUELA EN ESTADOS UNIDOS. Ficha técnica: comercio entre Venezuela y Estados Unidos. Ago. 2011. Disponível em: <http://venezuela-us.org/es/wp-content/uploads/2009/05/08-01-2011-fact-sheet-trade-spanish.pdf>. Acesso em: 4 jun. 2012.

EN AMÉRICA Latina felicitaron a Obama y calificaron de "histórico" su triunfo. Clarín, 5 nov. 2008. Disponível em: <http://edant.clarin.com/diario/2008/ 11/05/um/m-01796334.htm>. Acesso em: dez. 2012.

ERIKSON, Daniel. Obama \& Latin America: magic or realism? World Policy Journal, Winter 2008.

¿ESTADOS Unidos cambió su papel con América Latina? El País.com.co, 16 abr. 2012. Disponível em: <http://contenidos.elpais.com.co/elpais/colom- 


\section{Yes We Can? A Política Externa de Obama}

para a América Latina: Da Decepção...

bia/noticias/eeuu-cambio-su-papel-con-america-latina>. Acceso em: 20 abr. 2012.

GEDDA, G. Latin America: Back on the radar screen? Foreign Service Journal, jan. 2004.

ISACSON, Adam. Militarizing Latin America policy. Foreign Policy in Focus, 6 out. 2005. Disponível em: <http://www.fpif.org/reports/militarizing_latin_america_policy>. Acesso em: 24 abr. 2012.

LATINOAMÉRICA: cae popularidad de Obama. Voz de América, 13 abr. 2012. Disponível in: <http://www.voanoticias.com/content/latinoamerica popularidad_barack_obama_mexico_venezuela_bolivia/177612.html>. Acesso em: 24 abr. 2012.

LIEBERMAN, Robert. The politics of United States foreign policy under Barack Obama. Revista de Ciencia Política, v. 29, n. 3, p. 829-845, 2009.

LOWENTHAL, Abraham F. Estados Unidos y América Latina a inicios del siglo XXI. Foreign Affairs en Español, jan.-mar. 2007.

The Obama administration and the Americas. In: LOWENTHAL, A.; PICCONE, T.; WHITEHEAD, L. (Ed.). Shifting the balance: Obama and the Americas. Washington D.C: The Brookings Institution, 2011.

; PICCONE, T.; WHITEHEAD, L. (Ed.). Shifting the balance: Obama and the Americas. Washington D.C: The Brookings Institution, 2011.

MCCOY, J. The Chávez challenge for Obama: an inconvenient marriage or frosty separation. In: LOWENTHAL, A.; PICCONE, T.; WHITEHEAD, L. (Ed.). Shifting the balance: Obama and the Americas. Washington D.C: The Brookings Institution, 2011.

MIRANDA, Roberto. Bush-Obama y la continuidad de la sanción política a Argentina. Intellector, ano VIII, v. VIII, n. 16. jan./jun. 2012.

OBAMA, B. Renewing U.S. Leadership in the Americas. Real Clear Politics, 23 mai. 2008. Disponível em: <http://www.realclearpolitics.com/articles/ 2008/05/renewing_us_leadership_in_the.html>. Acesso em: 6 nov. 2012.

Nobel lecture. Nobelprize.org, 10 dez. 2009. Disponível em: $<$ htttp://www.nobelprize.org/nobel_prizes/peace/laureates/2009/obamalecture_en.html>. Acesso em: 3 jun. 2012. 
—. Why Haiti matters. Newsweek, 25 jan. 2010.

Mensaje de Barack Obama desde Santiago de Chile, mar. 2011. Disponível em: <http://www.flacso.org/uploads/media/Discurso_de_las_Americas. pdf>. Acesso em: 4 nov. 2012.

OBAMA'S letter to Lula regarding Brazil-Iran-Turkey nuclear negotiations. Política Externa Brasileira, 27 mai. 2010. Disponível em: <http://www.politicaexterna.com/11023/brazil-iran-turkey-nuclear-negotiations-obamas-letterto-lula>. Acesso em: 28 dez. 2011.

O'NEIL, S. Brazil as an emerging power: the view from the United States. SAIIA Policy Briefing 16, fev. 2010.

ROETT, R.; PAZ, G. (Ed.). China's expansion into the Western Hemisphere. Washington D.C.: The Brookings Institution, 2008.

RUSSELL, Roberto. América Latina para Estados Unidos: ¿especial, desdeñable, codiciada o perdida? Nueva Sociedad, n. 206, nov.-dez. 2006.

; TOKATLIAN, Juan Gabriel. Globalización y autonomía: una visión desde el Cono Sur. In: Universidad Torcuato Di Tella, Working Paper № 3, jul. 2000 .

SERBIN, Andrés. Cuando la limosna es grande. El Caribe, Chávez y los límites de la diplomacia petrolera. Nueva Sociedad, n. 205, p. 75-91, set./out. 2006.

SUÁREZ SALAZAR, L. La actual contra ofensiva plutocrática-imperialista contra las naciones y pueblos de "nuestra Mayúscula América”. ALAI, América Latina en Movimiento, 16 mar. 2011. Disponível em: <http://alainet. org/active/45135>. Acesso em: 5 nov. 2012.

SUOZZI, Marguerite. Arrecian críticas por presencia militar de EEUU. IPS, 26 jan. 2010. Disponível em: <http://ipsnoticias.net/nota.asp?idnews=94510>. Acesso em: 23 mai. 2012.

SUVER, Roman. Looking back on the Cuba distraction at Cartagena and the failure of the U.S. Latin America policy. Council on Hemispheric Affairs, 24 abr. 2012. Disponível em: <http://www.coha.org/looking-back-onthe-cuba-distraction-at-cartagena-and-the-failure-of-the-u-s-latin-americapolicy/>. Acesso em: 5 mai. 2012.

TUSSIE, Diana. Argentina y EE.UU. bajo el signo de la era K. In: ARNSON C.; TARACIUK, T. (Comp.). Relaciones bilaterales entre Argentina y Estados 


\title{
Yes We Can? A Política Externa de Obama para a América Latina: Da Decepção...
}

Unidos. Pasado y presente. Washington D.C.: Woodrow Wilson International Center for Scholars, 2004.

UN ENCUENTRO distendido para aliviar tensiones. Página/12, 5 nov. 2011. Disponível em: <http://www.pagina12.com.ar/diario/elpais/ 1-180576-2011-11-05.html>. Acesso em: 6 mai. 2012.

VALENZUELA, A. Las prioridades de la Administración Obama en América Latina. La Red 21, 24 jan. 2011. Disponível em: <http://www.lr21.com.uy/ contratapa/439016-las-prioridades-de-la-administracion-obama-en-americalatina>. Acesso em: 12 ago. 2012.

\section{Resumo}

\section{Yes We Can? A Política Externa de Obama para a América Latina: Da Decepção à Autonomização da Região}

\begin{abstract}
Este artigo busca investigar, descrever e refletir sobre o estado atual da política externa dos Estados Unidos para a América Latina, por meio de uma análise descritiva dos itens da agenda e do conteúdo da política externa, considerando a sua implementação em dois níveis de projeção: regional e bilateral (com base nos casos da Venezuela, do Brasil e da Argentina). Os objetivos específicos são entender: primeiro, as razões e a natureza da decepção regional em relação à política hemisférica da administração Obama; e, segundo, como se manifesta e como se reforça o distanciamento político estratégico entre os Estados Unidos e os três países selecionados, em função de fatores como a inércia na política externa, a ausência de uma nova e ativa estratégia diplomática e a autonomia crescente da região.
\end{abstract}

Palavras-chave: Administração Obama - Política Hemisférica - Autonomia 


\section{Abstract}

\section{Yes We Can? Obama's Foreign \\ Policy Towards Latin America: \\ From Disappointment to the Autonomization of the Region}

This article seeks to investigate, describe and reflect on the current state of United States foreign policy towards Latin America, through a descriptive analysis of agenda items in two levels: regional and bilateral (based on the cases of Venezuela, Brazil and Argentina). Specifically we seek to account for the reasons and nature of regional disappointment regarding President Barack Obama's hemispheric policy. Second, the article analyzes how the strategic political rift between the United States and the three selected countries manifests itself, in the context of factors such as foreign policy inertia, the absence of an active new diplomatic engagement, and the growing autonomy of the region.

Keywords: Obama Administration - Hemispheric Policy - Autonomy 